\title{
Pra Rancang Pabrik Pembuatan Asam Sulfat dari Sulfur, Oksigen, dan Air Menggunakan Proses Kontak dengan Kapasitas 160.000 Ton/Tahun
}

Resi Ulandari ${ }^{1}$, Lince Muis ${ }^{1}$, dan Ira Galih Prabasari ${ }^{1}$

${ }^{1}$ Program Studi Teknik Kimia, Fakultas Teknik, Universitas Jambi, Jambi, Indonesia

Email: resiulandari1090@gmail.com, lincemuisismet@yahoo.com, iragalih@gmail.com

\section{Info Artikel}

Diterima: 22 Desember 2019

Disetujui: 20 Januari 2020

Dipublikasikan: 30 Januari 2020

\section{Alamat Korespondensi: \\ resiulandari1090@gmail.com \\ Copyright (C) 2020 Jurnal \\ Engineering}

This work is licensed under the Creative Commons Attribution International License (CC BY 4.0).

\begin{abstract}
Abstrak
Pabrik pembuatan asam sulfat ini direncanakan berlokasi di daerah Prambonwetan, Jawa Timur dengan area luas 3,8 ha dengan kapasitas 160.000 ton/tahun. Proses pembuatan Asam Sulfat menggunakan bahan baku dari Sulfur, Oksigen dan Air dengan bantuan Vanadium Pentoksida sebagai katalis. Reaksi berlangsung di dalam Burner (B-01) sebagai pembentukan Sulfur Dioksida pada suhu $1000{ }^{\circ} \mathrm{C}$ dan tekanan 1 atm. Selanjutnya reaksi berlansung di dalam dua jenis reaktor yaitu Continuous Stirred Tank Reaktor (R-02) sebagai pembentukan Asam Sulfat pada suhu $80^{\circ} \mathrm{C}$ dan tekanan $1 \mathrm{~atm}$. Sedangkan reaktor Fixed Bed Multibed (R-01) tersusun atas 4 buah bed sebagai pembentukan Sulfur Trioksida dengan suhu masing-masing $450^{\circ} \mathrm{C}, 440^{\circ} \mathrm{C}, 425^{\circ} \mathrm{C}$, dan $405^{\circ} \mathrm{C}$ pada tekanan $1 \mathrm{~atm}$. Perusahaan berbentuk Perseroan Terbatas (PT) yang dipimpin oleh seorang Direktur Utama. Sistem organisasi perusahaan adalah line and stuff dengan total karyawan 210 orang. Hasil analisa ekonomi dari prarancang pabrik pembuatan Asam Sulfat ini adalah Biaya Produksi sebesar US \$ 2.711.778.745,5753, Hasil Penjualan sebesar US \$ 3.947.629.377,3979, Annual Cash Flow sebesar US \$ 811.552.893,4923, Pay Out time selama 3 tahun, Break Even Point 36,4319 \%, Service Life 11 tahun.
\end{abstract}

Kata kunci: Asam Sulfat, Sulfur, Oksigen, Air dan Proses Kontak

\section{Pendahuluan}

Perkembangan industri kimia di Indonesia saat ini cenderung mengalami peningkatan setiap tahunnya baik secara kuantitas maupun kualitas. Hal tersebut menyebabkan kebutuhan akan bahan baku maupun bahan penunjang akan meningkat pula. Perkembangan industri ini juga diiringi dengan peningkatan konsumsi masyarakat terhadap produk-produk industri. Produk-produk industri kimia saat ini telah menjadi kebutuhan hampir di semua bidang kehidupan sehari-hari. 
Asam sulfat merupakan salah satu bahan kimia yang sangat penting dan banyak dibutuhkan oleh industri-industri kimia, antara lain industri pupuk (digunakan untuk pembuatan super fosfat dan ammonium sulfat), pengolahan minyak bumi, farmasi, kertas dan pulp, plastik, baterai, bahan peledak, cat dan pigmen dan lainnya.

Semakin berkembangnya industri kimia di Indonesia, maka permintaan akan asam sulfat pada tahun-tahun mendatang juga akan bertambah. Oleh karena itu, pabrik asam sulfat perlu didirikan di Indonesia dengan pertimbangan sebagai berikut, yakni dapat menghemat devisa negara, dengan adanya pabrik asam sulfat di dalam negeri maka impor dapat dikurangi dan jika berlebih bisa untuk diekspor. Pendirian pabrik asam sulfat diharapkan akan mendorong berdirinya industri hilir yang menggunakan asam sulfat sebagai bahan baku dan bahan penunjang. Pendirian pabrik juga akan membuka lapangan kerja baru yang nantinya dapat mengurangi masalah pengangguran.

\section{Deskripsi Proses}

Bahan baku sulfur berupa padatan bubuk disimpan didalam tangki penyimpanan (T-01) pada kondisi temperatur $30{ }^{\circ} \mathrm{C}$ dan tekanan $1 \mathrm{~atm}$. Sulfur kemudian diangkut menggunakan bed elevator (BE-01) menunju melter (M-01) untuk proses pelelehan menjadi bentuk slurry. Sulfur yang telah berada di M-01 akan di lelehkan pada temperatur $140{ }^{\circ} \mathrm{C}$ dengan tekanan $1 \mathrm{~atm}$. Sulfur yang telah mencair atau telah membentuk slurry dikirim menggunakan heat belt conveyer (HBC-01) menuju burner (B-01). Heat belt conveyer (HBC-01) didesain tertutup yang berfungsi untuk menjaga suhu slurry agar tetap konstan sebelum masuk ke burner (B-01) dengan menggunakan steam. Bersamaan dengan itu dialirkan udara yang mengandung oksigen dan nitrogen kedalam B-01. Sebelum masuk B-01 udara terlebih dahulu ditarik oleh Blower (BL-01) menuju Heater-01 (HE-01), dengan tujuan menghilangkan kandungan air pada udara. Burner (B-01) difungsikan untuk mereaksikan sulfur dengan udara membentuk sulfur dioksida ( $\mathrm{SO} 2$ ) pada kondisi operasi temperatur $1000^{\circ} \mathrm{C}$ dan tekanan 1 atm dengan sifat reaksi eksotermis. Reaksi yang terjadi adalah:

$$
\mathrm{S}(\mathrm{g})+\mathrm{O} 2(\mathrm{~g}) \longrightarrow \mathrm{SO} 2(\mathrm{~g})
$$

Setelah terjadi proses reaksi pembentukan $\mathrm{SO}$, produk keluaran B-01 berupa gas proses didinginkan oleh WHB- 01 dari temperatur $1000^{\circ} \mathrm{C}$ menjadi $450{ }^{\circ} \mathrm{C}$ sebelum masuk ke reaktor FBR (R-01). Gas proses yang mengandung $\mathrm{SO} 2$, didalam R- 01 direaksikan dengan oksigen sisa untuk membentuk gas sulfur trioksida ( $\mathrm{SO} 3$ ) dan reaksi ini dibantu oleh katalis vanadium pentaokisda (V2O5). Reaksi yang terjadi adalah:

$$
\mathrm{SO} 2(\mathrm{~g})+1 / 2 \mathrm{O} 2(\mathrm{~g}) \longrightarrow \mathrm{SO} 3(\mathrm{~g})
$$

Reaktor fixed bed multibed (R-01) tersusun atas 4 buah bed, bed pertama kondisi operasinya pada temperatur $450^{\circ} \mathrm{C}$ dan tekanan $1 \mathrm{~atm}$. Bed 2 kondisi operasinya temperatur $440{ }^{\circ} \mathrm{C}$ dan tekanan $1 \mathrm{~atm}$, 
sehingga keluaran bed pertama temperaturnya turunkan menggunakan chiller-01 (CH-02) menjadi $440{ }^{\circ} \mathrm{C}$. Pada bed 3 kondisi operasinya pada temperatur $425{ }^{\circ} \mathrm{C}$ dan tekanan 1 atm, maka gas keluaran bed 2 diturunkan temperatur dari $440{ }^{\circ} \mathrm{C}$ menjadi $425{ }^{\circ} \mathrm{C}$ oleh cooler- 01 .

Hasil keluaran pada bed 3 masuk ke cooler- 02 (CO-02) untuk diturunkan temperaturnya dari 425 ${ }^{\circ} \mathrm{C}$ menjadi $405{ }^{\circ} \mathrm{C}$, penurunan ini dilakukan karena kondisi operasi bed 4 pada temperatur $405{ }^{\circ} \mathrm{C}$ dan tekanan $1 \mathrm{~atm}$. Gas proses keluaran R-01 dengan temperatur $405^{\circ} \mathrm{C}$ dialirkan ke chiller-02 (C-02) untuk diturunkan temperatur menjadi $200{ }^{\circ} \mathrm{C}$ sebelum masuk menara absorber (AB01).

Kemudian pada proses AB-01 merupakan proses penyerapan $\mathrm{SO} 3$ menggunakan absorben $\mathrm{H} 2 \mathrm{SO} 4$ menjadi $\mathrm{H}_{2} \mathrm{SO} 4$. .SO3. Gas proses keluaran pada R-01 masuk melalui bagian dinding bottom AB- 01, sedangkan absorben ( $\left.\mathrm{H}_{2} \mathrm{SO} 4\right)$ masuk melalui bagian dinding top AB-01. Reaksi yang terjadi adalah:

$$
\mathrm{SO}_{3}(\mathrm{~g})+\mathrm{H}_{2} \mathrm{SO} 4(\mathrm{l}) \quad \longrightarrow \quad \mathrm{H}_{2} \mathrm{SO}_{4} . \mathrm{SO}_{3}(\mathrm{l})
$$

Keluaran top AB-01 merupakan gas yang masih mengandung 97\% nitrogen (N2), sehingga gas tersebut disimpan pada tangki penyimpanan (T-02) dengan cara pemampatan menggunakan compressor01 (CP-01) pada tekanan $200 \mathrm{~atm}$ dan temperatur $-210^{\circ} \mathrm{C}$ untuk kondisi penyimpanan dengan fase liquid didalam tangki. Produk dari bagian bottom AB-01 yang berupa senyawa $\mathrm{H}_{2} \mathrm{~S}_{2} \mathrm{O} 4$..SO3 dipompakan P-01 masuk kedalam reaktor CSTR (R-02). Sebelum masuk kedalam R- 02, produk bottom AB-01 ini didinginkan dari keluaran temperatur $120^{\circ} \mathrm{C}$ menjadi $80^{\circ} \mathrm{C}$ menggunakan chiller-05 9 (CH-05). Didalam R-02 senyawa $\mathrm{H}_{2} \mathrm{~S}_{2} \mathrm{O}_{4} . . \mathrm{SO} 3$ direaksikan dengan $\mathrm{H}_{2} \mathrm{O}$ agar membentuk asam sulfat pada kondisi operasi temperatur $80^{\circ} \mathrm{C}$ dan tekanan 1 atm. Bahan baku $\mathrm{H}_{2} \mathrm{O}$ yang masuk ke R-02 juga sebelumnya dinaikkan temperatur oleh heater-02 (HE-menjadi $80^{\circ} \mathrm{C}$. Reaksi yang terjadi

adalah:

$$
\mathrm{H}_{2} \mathrm{SO}_{4} . \mathrm{SO} 3(\mathrm{l})+\mathrm{H}_{2} \mathrm{O}(\mathrm{l}) \longrightarrow 2\left(\mathrm{H}_{2} \mathrm{SO}_{4}\right)(\mathrm{l})
$$

Asam sulfat 98\% yang terbentuk dari R-02 dipompakan P-02 menuju tangki penyimpanan (T-01), dimana sebelumnya produk asam sulfat didinginkan oleh 2 buah cooler Cooler-01 dan Cooler-02 ke temperatur $30{ }^{\circ} \mathrm{C}$. Setengah produk asam sulfat di alirkan oleh P-03 kembali menuju AB-01 sebagai absorben. 


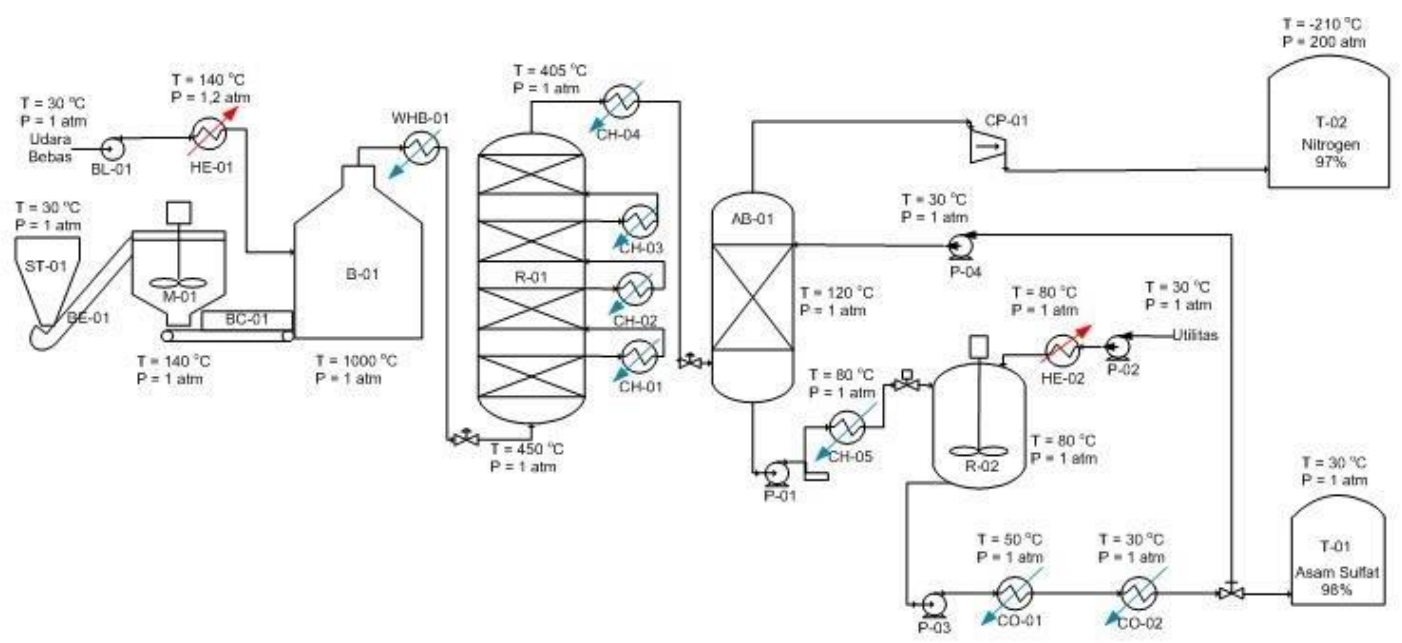

\begin{tabular}{|c|c|c|c|}
\hline $\begin{array}{l}\text { KODE } \\
\text { ALAT }\end{array}$ & KETERANGAN & $\begin{array}{l}\text { KODE } \\
\text { ALAT }\end{array}$ & KETER_ANGAN \\
\hline $\begin{array}{l}\mathrm{AB} \\
\mathrm{B} \\
\mathrm{BC} \\
\mathrm{BE} \\
\mathrm{CH} \\
\mathrm{CO} \\
\mathrm{H}\end{array}$ & $\begin{array}{l}\text { ABSORBER. } \\
\text { BURNER. } \\
\text { BELT CONTEYOR } \\
\text { BUCKET ELEVATOR } \\
\text { CHILER. } \\
\text { COOLER. } \\
\text { HEATER. }\end{array}$ & $\begin{array}{c}M \\
K \\
P \\
R \\
R B \\
S T \\
T \\
\text { WHB }\end{array}$ & $\begin{array}{c}\text { MIELTER } \\
\text { KONPRESOR } \\
\text { PONPA } \\
\text { REAKTOR } \\
\text { REBOILER } \\
\text { SILO } \\
\text { TANCKI } \\
\text { WASTE HEAT BOILER }\end{array}$ \\
\hline
\end{tabular}

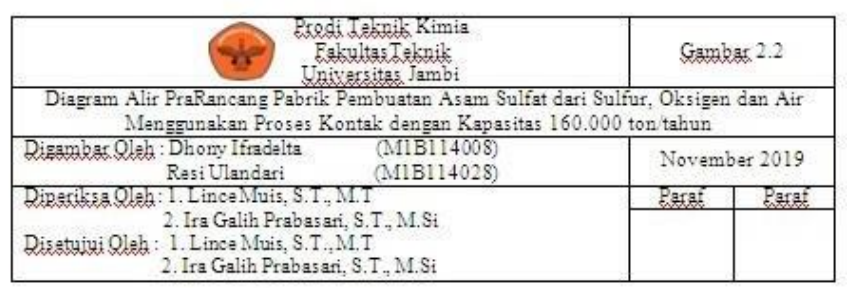

Gambar 1. Flowsheet Pembuatan Asam Sulfat

\section{Tata Letak Pabrik}

Salah satu hal yang sangat penting dalam perencanaan suatu pabrik adalah pemilihan dan penentuan lokasi berdirinya pabrik karena akan berpengaruh terhadap kelancaran kegiatan produksi dan distribusi produk. Hal ini juga sangat menentukan kemajuan pabrik tersebut, baik pada saat berproduksi maupun pada masa yang akan datang. Penentuan lokasi pabrik sangat mempengaruhi kegiatan pabrik,baik menyangkut produksi maupun distribusi produk. Oleh karena itu penentuan lokasi pabrik harus memberikan perhitungan biaya produksi dan biaya distribusi yang minimum. Adapun faktor-faktor yang menjadi dasar pertimbangan dalam menentukan lokasi pabrik adalah yaitu Penyediaan bahan baku, Pemasaran hasil produksi, Transportasi dan distribusi, Utilitas, Penyediaan tenaga kerja, Keadaan iklim. Berdasarkan beberapa pertimbangan diatas maka direncanakan pendirian pabrik asam sulfat yang berlokasi didesa Prambonwetan Kecamatan Rengel Kabupaten Tuban Provinsi Jawa Timur Peta lokasi pabrik dapat dilihat pada gambar 2 . 


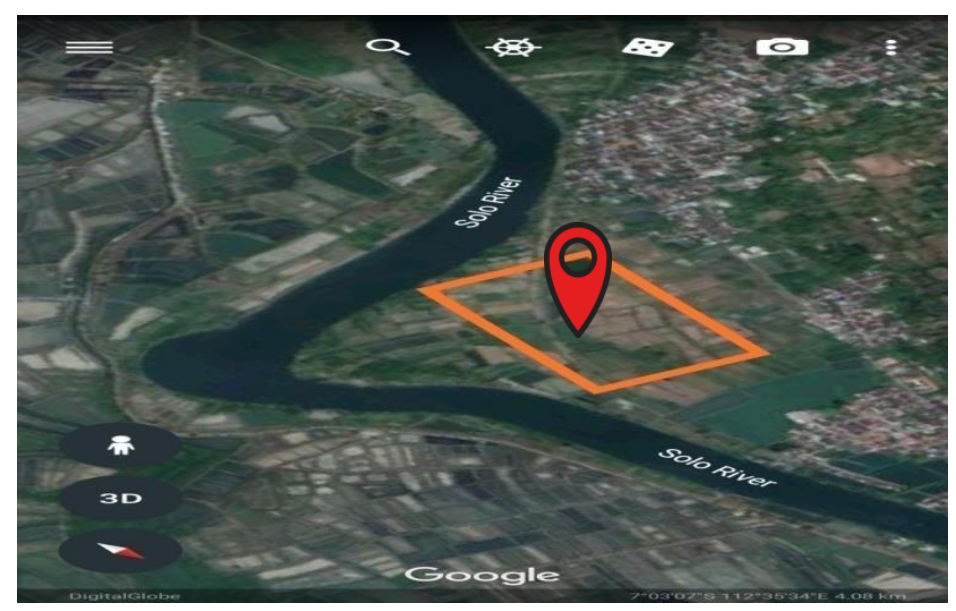

Gambar 2. Lokasi Pabrik berdasarkan Google Maps

\section{Analisa Ekonomi}

Berdasarkan perhitungan analisa ekonomi dari pra rancangan pabrik ini didapatkan bahwa :

1. Annual Cash Flow $(\mathrm{ACF})=$ US $\$ 811.552 .893,4923$ dimana nilainya lebih besar dari bunga bank $(>5,47$ $\%)$

2. Pay Out Time (POT) $=3$ tahun dimana $<$ dari setengah umur pabrik (umur pabrik $=11$ tahun)

3. Net Profit Over Total Lifetime of The Project (NPOTLP) $=$ US\$ 8.836.993.943,6522 dimana nilainya $>$ dari TCI + total bunga pinjaman ( >US\$ 122.191.554,5095)

4. Total Capital Sink (TCS) $=$ US\$ 8.811.089.093,4055 > dari Total Capital Investment (>US\$ 113.323.939,6651)

5. Rate of Return on Investment (ROI) $=7,0886 \%$ dimana nilainya $>$ bunga bank $(>5,47 \%)$

6. Rate of Return based on Discounted Cash Flow (DCF) $=7.1614 \%$ dimana nilainya $>$ dari bunga bank $(>5,47 \%)$

7. Break Even Point $(\mathrm{BEP})=36,43 \%$, dimana nilai BEP $20 \%<$ BEP $<40 \%$

Secara keseluruhan, Pra Rancangan Pabrik Pembuatan Asam Sulfat ini memenuhi semua parameter analisa ekonomi, Oleh karena itu, pabrik pembuatan Asam Sulfat ini layak untuk didirikan.

\section{Tugas Khusus: Reaktor CSTR}

Reaktor tangki berpengaduk aliran kontinyu atau CSTR terdiri dari tangki yang dilengkapi dengan motor pengaduk. Beberapa reaktor dapat dipasang secara seri maupun paralel. Reaktor stirred tank digunakan untuk reaksi homogen (liquid- liquid), reaksi heterogen (liquid-gas) dan reaksi yang melibatkan padatan tersuspensi yang dibantu dengan adanya pengadukan. Kebanyakan aplikasi dari tangki berpengaduk digunakan pada operasi kontinyu. Pengadukan sempurna penting agar dapat meningkatkan kinerja sebagai reaktor. 
Dalam CSTR, aliran reaktan dan aliran produk akan terus mengalir. Selama proses bahan baku dimasukkan terus menerus demikian juga dengan produk reaksi akan dikeluarkan secara terus menerus atau kontinyu. Dalam pengoperasian CSTR diperlukan pengadukan mekanik atau hidrolik untuk mencapai komposisi dan suhu yang seragam.

Spesifikasi CSTR

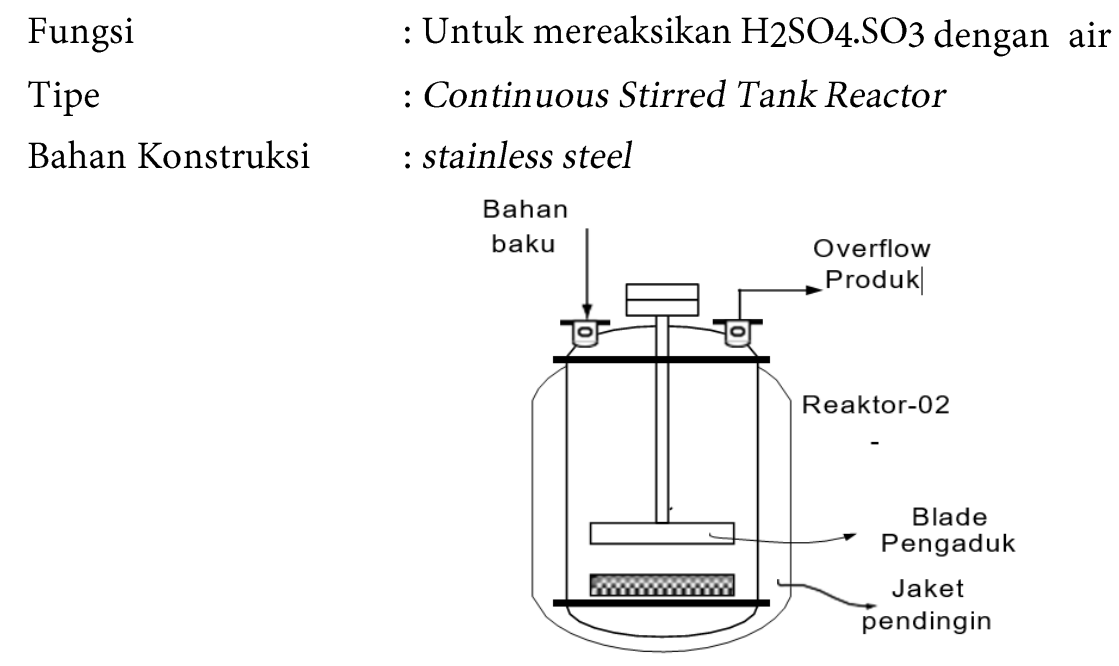

Gambar 2. Reaktor CSTR

\begin{tabular}{lc}
\hline & IDENTIFIKASI \\
\hline Nama alat & CSTR \\
Kode alat & R-02 \\
Jumlah & 1 buah \\
Fungsi & Untuk mereaksikan asam pirosulfat dan air \\
Tipe & Continuous Stirred Tank Reactor \\
\hline & DATA DESAIN \\
\hline Temperatur desain & $80^{\circ} \mathrm{C}$ \\
Tekanan desain & 1 atm \\
Kapasitas & $12,6075 \mathrm{~m}^{3}$ \\
\hline & Data Mekanik \\
\hline Tipe pengaduk & disk flate blade turbine \\
Diameter vessel & $2,9591 \quad \mathrm{~m}$ \\
Tinggi silinder & $4,4387 \quad \mathrm{~m}$ \\
Tinggi tutup & $0,7398 \quad \mathrm{~m}$ \\
Tinggi total tangki & $5,9183 \quad \mathrm{~m}$ \\
Tinggi liquid & $3,1071 \mathrm{~m}$ \\
Diameter impeller & $0,5918 \quad \mathrm{~m}$
\end{tabular}




$\begin{array}{lll}\text { Lebar baffle } & 0,2959 \mathrm{~m} \\ \text { Lebar baffle pengaduk } & 0,5918 \mathrm{~m} \\ \text { Panjang blade pengaduk } & 0,7398 \mathrm{~m} \\ \text { Posisi baffle dari dinding tangki } & 0,0616 \mathrm{~m} \\ \text { Tebal tangki } & 00,0050 \mathrm{~m} \\ \text { Tebal jaket pendingin } & 0,0037 \mathrm{~m} \\ \text { Kecepatan putaran pengaduk } & 3,3723 \mathrm{Rps} \\ \text { Tenaga pengaduk } & 45,4213 \mathrm{Hp} \\ \text { Bahan konstruksi } & \text { Carboon steel }\end{array}$

\section{KESIMPULAN}

Dari hasil analisa dan perhitungan pra rancangan pabrik asam sulfat dari sulfur dan udara menggunakan proses kontak dengan kapasitas 160.000 ton/tahun diperoleh beberapa kesimpulan, yaitu:

1. Kapasitas produksi asam sulfat 160.000 ton/tahun menggunakan bahan baku sulfur dan udara sebanyak $9305,5556 \mathrm{~kg} / \mathrm{jam}$

2. Berdasarkan faktor bahan baku, transportasi, pemasaran dan bahan penunjang, pabrik asam sulfat akan didirikan didesa Prambonwetan Kecamatan Rengel Kabupaten Tuban Provinsi Jawa Timur

3. Perusahaan berbentuk Perseroan Terbatas dengan struktur organisasi line and staffyang dipimpin oleh direktur beserta jajaran direksi dengan jumlah karyawan sebanyak 210 orang.

4. Luas tanah yang dibutuhkan untuk pembangunan pabrik asam sulfat ini yaitu $38281 \mathrm{~m}^{2}$

5. Berdasarkan hasil analisa ekonomi, pabrik asam sulfat ini dinyatakan layak untuk didirikan, dengan rincian:
a. Biaya Produksi (TPC) : US\$2.711.778.745,5753
b. Hasil Penjualan (SP) : US\$ 3.947.629.377,3979
c. Annual Cash Flow : US\$ 811.552.893,4923
d. Pay Out Time : 3 tahun
e. Return on Investment : 7,0886\%
f. Break Even Point : $36,4319 \%$
g. Service Life : 11 tahun

\section{DAFTAR PUSTAKA}

[1] Badan Pusat Statistik Indonesia. 2019 Coulson, J.M., Richardsons, J.F., Sinnot

[2] R.K., 1983, "Chemical Engineering Design", volume 6, Pergamon Press.

[3] Daubert, Thomas E., "Chemical Engineering Thermodynamics", 1985, $3^{\text {rd }}$ edition, Mc. Graw Hill Book Company, New York. 
[4] Felder, R. M., \& Ronald, W. R. 2005. Elementary Principles of Chemical Processes, $3^{\text {rd }}$ Edition. New York: John Wiley \& Sons, Inc.

[5] Geankoplis, C. J. 1993. Transport Processes and Unit Operations. New Jersey : Prentice - Hall, Inc.

[6] Google Maps. 2018. Google Maps. (Online). http://www.google.co.id/maps/place. Diakses pada tanggal 15 Januari 2019.

[7] Hadi, A. 2007. Pengolahan Limbah Cair Industri. Jurnal Prinsip Pengelolaan Pengambilan Sampel Lingkungan, (Hal: 1-40)

[8] Holleman, A.F \& Wiberg E. 2001. Inorganis Chemistry. Academic Press: San Diego

[9] Ismail, S. 1999. Alat Industri Kimia. Unsri: Palembang

[10] Kern, D.Q. 1965. Process Heat Transfer. Mc Graw-Hill Book Co: New York.

[11] Levenspiel, Octave. 1999. Chemical Reaction Engineering, Th ird Edition. John Wiley \& Sons Inc: USA.

[12] Masterton, William L \& Cecile N Hurley. 2008. Chemistry: Principles and Reactions. Brooks/Cole Cengage Learning:USA.

[13] Matches. 2015. Matche's Process Equipment Cost Estimates. (online). www.matche. com. (Diakses 10 Januari 2019).

[14] McCabe, W. L., 1995. Unit Operations of Chemical Engineering.McGraw- Hill Book Co: New York.

[15] Perry, R.H. 1999. Perry's Chemical Engineer's Handbook, $7^{\text {th }}$ Edition. McGraw-Hill Book Co: New York.

[16] Peters, M.S. dan K.D.Timmerhaus. 1991. Plant Design and Economics for Chemical Engineers, Fourth Edition. Mc Graw-Hill Book Co: New York.

[17] Sinnot, R. K. 2005. Coulson \& Richardson's Chemical Engineering, Volume 6, Fourth Edition: Chemical Engineering Design. Elsevier Butterworth- Heinemann: Oxford

[18] Smith, J.M. dan H. C. Van Ness. 2001. Introduction to Chemical Engineering Thermodynamics, Sixth Edition. Mc Graw-Hill Book Co: New York.

[19] Walas, S.M. 1990. Chemical Process Equipment Selection and Design. Butterworth-Heinemann: New York.

[20] Yaws, C.L. 1999. Chemical Properties Handbook. McGraw-Hill Book Co: New York. 